\title{
Efficiency, Feasibility and Desirability of Learner Autonomy Based on Teachers' and Learners' Point of Views
}

\author{
Somayeh Shahsavari \\ Islamic Azad University, Science and Research Branch of Isfahan, Iran
}

\begin{abstract}
Learner autonomy has been a recent trend in education which highlights the students' engagement in their own learning. Although over the past 30 years, a large body of research has been carried on learner autonomy, limited attention has been paid to the sense teachers in comparison to learners would make of this concept. The present study is an attempt to shed light on the general existing pattern of the way teachers and learners view learner autonomy. To do so, applying the convenience method of sampling, a structured questionnaire consisting of five sections was emailed to most of the teachers teaching English as a foreign language in Isfahan, Iran. In order to have a more precise analysis, an interview was carried out to see what reasons are behind the participants' answers. Employing the referential statistics, the results indicated that nearly all the teachers and learners agreed on the fact that learner autonomy allows language learners to learn more efficiently than they otherwise would. Furthermore, in relation to desirability and feasibility of learner autonomy, almost all the participants agreed that it is more desirable than feasible. The findings of this study might benefit those teachers and institution officials interested in enhancing learning autonomy among their students and even educating themselves or the other teachers to make use of it practically in classrooms.
\end{abstract}

Index Terms - learner autonomy, efficiency, feasibility, desirability

\section{INTRODUCTION}

Language learning is one of the most challenging activities one has to deal with. Such lifelong learning process, obviously, involves making a good use of the latest methods, strategies, technologies and materials and even attitudes. Therefore, regarding the noticeable speed of technology enrichment in the field of second/foreign language learning (ESL/EFL), as well as, the new strategies and methods, it is really crucial to take steps in the right directions to train better language learners. There are many different influencing strategies which can efficiently help the learners become able to compensate for this high-speed advancement of technology. One of these efficient strategies or better to say attitudes is making the best efforts to educate independent as well as autonomous language learners in order to provide them with opportunities to take charge of their own learning. To do so, being aware of teachers' and learner's perceptions of the term is really important since it can powerfully affect the selection of methods, materials, activities and so forth. Autonomy does not mean a new methodology but an attitude adopted by the learner in his/her learning process which is based on the learner's responsibility needed to be recognized and improved (Andreu, 2007). So, as long as teachers are not aware of the ways to make their students responsible of their own learning in the way of becoming autonomous learners, the classroom will remain a place where students have to go with the only aim of passing the exams fixed in their curriculum. Therefore, as a teacher, one of the most important moral duties which is expected to be considered is to help students become more independent and autonomous.

However, it has been approved that during the last decades, a large body of research has been performed to investigate what autonomy is, how it can be promoted, or even the interrelationship between autonomy and gender, learning styles, motivation, teaching and learning activities.

Nevertheless, little has been done in the field of teachers' beliefs and perception of the matter. In fact, it is not known that whether teachers generally accept the views about learner autonomy or even to what extent they know about it. Palfreyman (2003) did acknowledge the gap that may exist between theoretical discussions of learner autonomy and teachers' own perceptions of the concept and made the point with specific reference to the manner in which learner autonomy has been conceptualized from technical, psychological, and political perspectives (Benson, 1997) and, additionally, from a sociocultural perspective (Oxford, 2003). Furthermore, most of the studies in the field of beliefs on learner autonomy have aimed to delve into the meaning of autonomous language learners and little is related to the teachers' beliefs, perceptions and ideas, in comparison with their learners' opinions. Actually, it is not exactly clear if generally language teachers come to a common point of view and whether learners' perception toward the matter is significantly different or not. The present study, consequently, is an attempt to fill the existing gap.

Experience in language institutes reveals the fact that students usually come to these centers with limited study skills and they only depend on their teachers to improve their language skills. Therefore, EFL teachers need to train their students in skills and techniques which will enable them to be more independent and effective learners in higher levels. 
In this regard, we need to be informed whether learning to become autonomous is reliable and feasible also, we need to become aware of the challenges which teachers and learners encounter in this learning process.

Moreover, some individual, pair and group work learning activities, such as working with multimedia software, checking the words in dictionaries, studying supplementary books for further practice, and doing some projects like surfing an article online or writing a piece of paper are proposed and utilized in these institutes; however, there is a concern among both managers and teachers that whether the existing activities are beneficial and efficient or not.

In general, it seems that even language teachers, especially the novices are not familiar with the concept of learner autonomy so, they are not able to develop it in their learners. Therefore, it is vital for both the experienced and the novice teachers to become aware of the concept of learner autonomy, the characteristics of autonomous language learners, the ways to develop and enhance it and the ways and means to deal with the challenges practically. Therefore, being aware of teachers' and learners' beliefs of the matter can be regarded as the first step to promote learner autonomy and make use of the most influential autonomous activities in EFL classes.

In the present research the following questions are going to be answered:

1. Do L2 teachers and learners believe that learner autonomy would enhance L2 learning? If yes, to what extent?

2. Do L2 teachers and learners believe that the promotion of L2 learner autonomy is desirable and feasible? If yes, to what extent?

3. Are there any significant differences between L2 teachers' and Learners' beliefs regarding the degree of L2 learning enhancement through autonomy and desirability and feasibility of L2 learning autonomy promotion?

\section{REVIEW OF RELATED LITERATURE}

Although much has been written about learner autonomy, there has been little research carried out into teachers' perspectives so no much is known about what learner autonomy means to language teachers in various contexts and educational settings around the world (Borg, 2003). Due to the fact that teachers play a crucial role in the promotion of learner autonomy, addressing their beliefs in this area is effectively influential. In this section some studies which have explored teachers' beliefs about learner autonomy are discussed.

As far as this study investigates, Camilleri (1999) had done the first study to investigate teachers' views about learner autonomy. The study was carried out with teachers in various European countries. The main findings were:

- A willingness of teachers to change and develop practice

- Strong support in incorporating learner autonomy in different areas of teaching (material selection, areas of classroom management, learning strategies, learning styles)

- A reluctance of teachers to involve learners in aims and methodological decisions

- Constraints from higher authorities made it hard to encourage learner autonomy or offer more learner choice

Camilleri, on the other hand, (1999) presented questionnaire data collected from 328 teachers in six European contexts (Malta, The Netherlands, Belorussia, Poland, Estonia and Slovenia). The questionnaire consisted of 13 items each asking about the extent to which learners, according to the teachers, should be involved in decisions about a range of learning activities, such as establishing the objectives of a course or selecting course content. As a result, teachers were found to be positive about involving learners in a range of activities, such as deciding on the position of desks, periodically assessing themselves and working out learning procedures. In contrast, teachers were not positive about learner involvement in the selection of textbooks and deciding on the time and place of lessons.

In another study, Chan (2003) examined teacher's perspectives of learner autonomy in a large-scale study at the Hong Kong Polytechnic University. Her findings show that teachers felt mainly responsible for the methodological decisions within the classroom. Moreover, respondents reported a clear awareness of autonomy as a goal of teaching and felt fairly positive about students' decision making abilities in different aspects of the language learning process. Teachers did feel, however, restricted by curriculum constraints and consequently did not provide decision-making opportunities for learners in areas of autonomous learning (e.g. learning objectives, activities). This study reveals the fact that learner autonomy cannot be encouraged without support from the teacher. In addition, it shows that thinking about our beliefs and teaching practices is important as it allows for reflection and change if needed. The instrument from the above study was used once again by Balçıanlı (2010) to examine the views about learner autonomy of 112 student teachers of English in Turkey. Additionally, 20 participants were interviewed in focus groups of four teachers each. The results suggested that the student teachers were positively disposed towards learner autonomy - i.e. they were positive about involving students in decisions about a wide range of classroom activities, though, again, they were less positive about involving students in decisions about when and where lessons should be held. Al-Shaqsi (2009) was another survey of teachers' beliefs about learner autonomy. This was conducted with 120 teachers of English in state schools in Oman. A questionnaire was devised specifically for this study and it asked respondents about (a) the characteristics of autonomous learners (b) their learners' ability to carry out a number of tasks (each of which was assumed to be an indicator of learner autonomy - e.g. deciding when to use a dictionary or identifying their own weaknesses) and (c) how learner autonomy might be promoted. The three characteristics of autonomous learners most often identified by teachers were that they can use computers to find information, use a dictionary and ask the teacher to explain when they do not understand. The teachers in this study also assessed their learners positively on all of the indicators of learner autonomy they were presented with. The three most highly rated indicators were asking the teacher 
to explain when something is not clear, giving their point of view on topics in the classroom and using the dictionary well. The final study presented here is Martinez (2008), who examined, using a predominantly qualitative methodology, the subjective theories about learner autonomy of 16 student teachers of French, Italian and Spanish. These students were studying at a university in Germany and were taking a 32-hour course about learner autonomy at the time of the study. Data were collected through questionnaires, interviews, and observations during the course; copies of the instruments were, though, not included with the paper and it was not possible therefore to critique or draw on these in this study. Results showed that student teachers had positive attitudes towards learner autonomy and that these were informed largely by their own experiences as language learners. The conceptions of autonomy held by the student teachers generally reflected the view that (a) it is a new and supposedly better teaching and learning methodology; (b) it is equated with individualization and differentiation; (c) it is an absolute and idealistic concept; (d) it is associated with learning without a teacher. Such perspectives do not align with those currently promoted in the field of language teaching (and actually reflect several of the claims Esch (1998), above, made about what learner autonomy is not).

Bullock (2011) conducted a small-scale study of English language teachers' beliefs about learner self-assessment which highlights a gap between teachers' positive theoretical beliefs about this notion and their beliefs in its practicality.

Nakata (2010) compared English language teachers' (positive) theoretical views about the value of learner autonomy with their (less positive) reported classroom practices (and finds a substantial gap between the two). Both these studies, then, add to existing concerns in the literature that learner autonomy is a notion around which theoretical ideals and pedagogical realities may not always concur.

Reviewing the literature on learner autonomy reveals the fact that although a large body of research has be carried out to investigate learners' views toward learner autonomy, little has been done on explore teachers' point of view.

\section{METHODOLOGY}

\section{A. Participants}

The participants of this study were divided into two groups, including the EFL teachers and learners. In order to have a large number of participants to be able to generalize the gained results, two different methods of sampling i.e. snowballing and convenience sampling were employed. It was done through sending emails or asking the participants to fill out the questionnaires in print.

The population from which the group of teachers was chosen consisted of nearly all the teachers, teaching English as a foreign language at Gooyesh Language Institute (GLI, an English language institute with ten branches all over the city of Isfahan) and many other teachers in other institutes in Isfahan, as well. Due to the fact that the population was really big at first, an opportunity was created to select only the experienced teachers out of all the participants (It should be noted that the final selection of teachers was done after filling out the questionnaires). Therefore, the chosen group of teachers included 150 male ones having more than five years of experience in teaching English, being originally from Isfahan, having not been to any other countries, holding bachelor's, master's or doctorate degrees just in TEFL. This way the negative effects of diversity in the above factors were ruled out of the results of the study.

The second group of the participants consisted of the students chosen from the same language centers out of which the teachers were selected. Regarding the proficiency level, in order to have a homogeneous group of students, this study made an attempt to select only those students who passed the advanced levels of the language institutes and attended in the preparation courses for TOEFL. Therefore, it was possible to become convinced of the fact that all the students are proficient enough to take part in this research and they are able to comprehend and answer the questions as well. Since the purpose of the study was to gain the general pattern of the existing view point of the learners, the factors such as age range, gender and culture were not strictly controlled. Nevertheless, for minimizing the negative impact of the above factors, among all the learner participants only those who were male, originally from Isfahan, in 25 to 40 age range, having not been to any other countries and holding at least bachelor's degree were selected. With regard to the number of the teacher participants, 150 learner participants who had the above characteristics were selected.

\section{B. Instrument}

The instruments used for collecting the required data were a structured questionnaire and an interview.

\section{Questionnaire}

Questionnaires are inaccurately considered to be an easy to use instrument for collecting data in research. It is undeniable that they possess several advantages in comparison to other instruments, for example, they can be administered relatively economically, can reach a large number of participants in geographically diverse areas and can be analyzed quickly (Dörnyei\& Taguchi, 2010). However, such merits are futile if the questionnaire is not welldesigned. So, with regard to the fact that a comprehensive and complete questionnaire is required, this study has made a good use of the existing questionnaires designed by Borg \& Al-Busaidi, (2012). They took a noteworthy amount of time to prepare the questionnaire.

\section{Interview}

Interview was the other instrument employed (after the questionnaires were filled out). The questions for the interview were prefabricated and they were about more personal information related to the answers the participants gave in the questionnaires to see what reasons were behind their answers. In order to develop the interviews, the 
questions were designed based on what the participants chose and wrote on the questionnaire; they were asked to clarify their answers by reasoning, giving examples and explanations. The participants were also asked to talk about the challenges they have encountered in this regard. Therefore, the interviews helped the researcher analyze the participants' answers better and more precisely. One example of an interview schedule can be found in Appendix C.

\section{PROCEDURE}

\section{A. Phase 1}

As beforehand mentioned, in order to design the questionnaire which was used in this study, a systematic method was employed (Borg \& Al-Busaidi, 2012). Although one may make sure that this questionnaire is reliable, it was piloted in a population of 30 teachers. Applying SPSS 18, the value of Cronbach's alpha was found to be 0.87 which confirmed the reliability of the questionnaire. In order to check the validity of the questionnaire it was given to four experts (university teachers who teach testing) and they were kindly asked to check its content validity. They all expressed their agreement about relevance of the content validity of the questionnaire. Making use of convenience and snow-balling methods of data collection, these questionnaires were distributed among more than a thousand teachers in Isfahan through emails or on papers.

Prior to having been invited to complete questionnaires, the teachers had received an email with information about the study and explanation of the concept of learner autonomy. Then, a day later a request was sent and they were asked to fill out the attached questionnaire as soon as possible. Moreover, they were kindly asked to do their best to contribute it toward other teachers they know. This process lasted almost three months. After receiving about 324 responses from teachers, demographic parts of these completed questionnaires were investigated and only 150 ones who were male, originally from Isfahan, more than five years experienced, holding bachelor's, master's or doctorate degrees, were included to play a role in results of the study. Eventually, another email was sent to thank those who sent back the questionnaires.

\section{B. Phase2}

This phase of the study was made up of follow-up interviews with teachers who filled in the questionnaires and volunteered to speak (the ones who were eager to take part in the interview wrote their names at the bottom of their questionnaire). The interviews were carried out for the purpose of exploring the reasons of teachers' responses in more detail in order to provide the possibility of analyzing the questionnaires with highest accuracy. All the interviews were held in the participants' first language to let them clarify their reasons in detail effortlessly. Furthermore, getting permission for the volunteers in advance, they were audio recorded for further analysis. Out of the 150 selected questionnaires respondents, 48 volunteered to do an interview. As handling the interview with all these volunteers was really time-consuming and daunting, among them all, merely 30 participants were chosen to be interviewed. These 30 teachers were selected using criteria from two specific questionnaire responses: (a) teachers' beliefs about how autonomous their students were and (b) teachers' years of experience in ELT. Each interview lasts for almost 25 minutes. These 30 interviews took place nearly 15 days; all interviews were conducted face-to-face and audio recorded.

\section{Phase 3}

As this phase of the study deals with acquiring the learners' beliefs and perceptions toward learning autonomy, the students' questionnaire (which was piloted in a group of 42 advanced-level students; the amount of Cronbach's alpha for this questionnaire was calculated to be 0.81) were printed and given to the students who passed the advanced levels of the language institutes and attended in the preparation courses for TOEFL exam. After filling out the questionnaires by the learners, an attempt has been made to select only those students who were studying in advance levels of the same institutes from which the selection of the teachers had been done; thus, analyzing the data could be more valid. Owing to the fact that the students may have difficulties in answering the items of questionnaire, the researcher herself, explained the topic and objectives of the study to them and gave the questionnaires and helped them with their questions as well.

As managing an interview with all the students was kind of difficult, the questions of the interview were also printed and given to the students. However, based on the mentioned criteria which were used for the selection of the teachers to be interviewed, the learners were chosen, and then they were asked to take time answering the open ended questions of the interview in the presence of the researcher to answer probable questions.

\section{ANALYSis}

Aiming at answering the first question, items 8 and 21 of the first part of the questionnaire were seen influential. There is also a section in the questionnaire which is related to feasibility and desirability. Therefore, the second research question was answered based on the items of this part of the questionnaire. The final research question was a kind of comparative one, so the obtained data of the previous parts were compared and contrasted.

In the case of analyzing the questions, SPSS18 was made use of and the data obtained from teachers' and students' questionnaires and interviews were analyzed statistically. Descriptive statistics including frequency counts and 
percentages were calculated for the two questions then, the frequency tables and bar graphs were drawn for each one. Inferential statistics also used to investigate the relationships, similarities as well as differences among the variables.

However, the information gained from interviews was categorized through the process of qualitative thematic analysis (see, for example, Newby, 2010). This process involved reading the data carefully, identifying crucial factors and issues, and then classifying these issues into a set of broader categories. The questions in the questionnaire and the interview provided a structure within which specific answers could then be further categorized. It should be pointed out that the items of the interview gave us a support to see what the reasons are regarding the answers (which the participants gave beforehand).

\section{A. Addressing the First Research Question}

Do L2 Teachers and Learners Believe that Learner Autonomy Would Enhance L2 Learning? If Yes, to What Extent?

In order to answer the first research question, items 8 and 21 of the first part of the questionnaire were taken into account. These two questions were:

- Learner autonomy allows language learners to learn more effectively than they otherwise would

- Learner autonomy has a positive effect on being a successful language learner

All the participants expressed the degree of their agreement-disagreement on five point Likert scale ranging from 0 for "strongly disagree", to 4, for "strongly agree". Then the teachers and learners opinions about these two items were analyzed statistically. In order to investigate the teachers' and learners' views about the effect of the learner autonomy on language learning, descriptive statistics (frequency tables and bar graph) was employed.

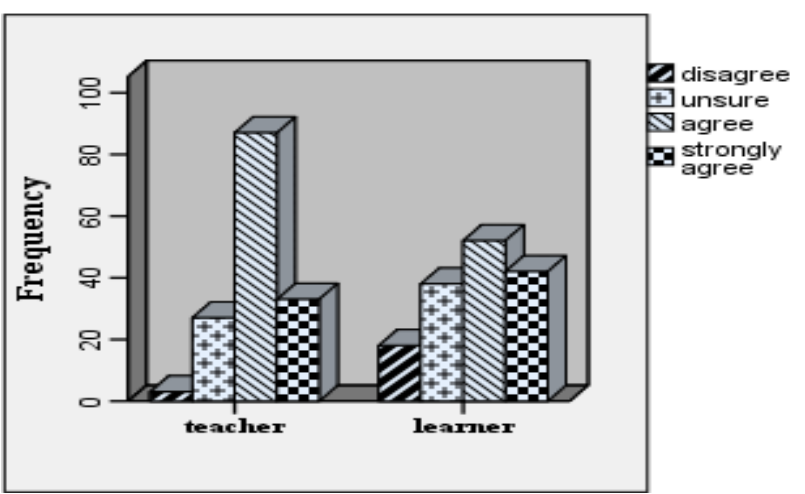

Figure 5.1. The Frequency Graph of the Question Does Learner Autonomy Allow Language Learners to Learn More Effectively Than They Otherwise Would?

The results demonstrate that more than a half of learners (62.7 percent) agreed or strongly agreed that learner autonomy allow them to learn more effectively than they otherwise would. On the other hand, almost all the teachers (80 percent) agreed or strongly agreed that learner autonomy has the above effect.

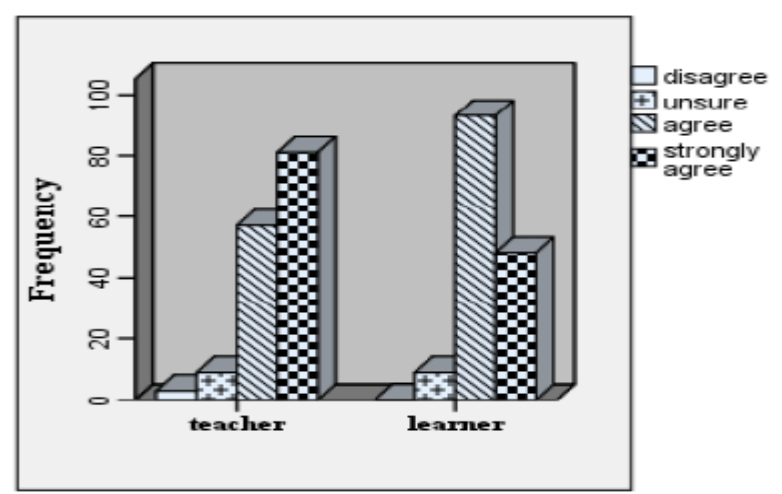

Figure 5.2. The Frequency Graph of the Question Does Learner Autonomy Have a Positive Effect on Being a Successful Language Learner?

The above figure shows that nearly all of the teachers (92 percent) and learners ( 94 percent) agreed or strongly agreed that learner autonomy has a positive effect on being a successful language learner.

\section{B. Addressing the Second Research Question}

Do L2 Teachers and Learners Believe that the Promotion of L2 Learner Autonomy Is Desirable and Feasible? If Yes, to What Extent?

As beforehand discussed, having decided to answer this question, the data obtained from second section of the questionnaire which is about desirability and feasibility of the learner autonomy was analyzed. Section 2 of the 
questionnaire addressed two issues. The first was the desirability and feasibility of involving learners in a range of language course decisions and the second includes desirability and feasibility of the learners' abilities.

The procedure of Likert scale ranging from 1 for "strongly disagree", to 4, for "strongly agree" was employed here to ask the learners to answer the questions of this section. Descriptive statistics was used for all the questionnaire items.

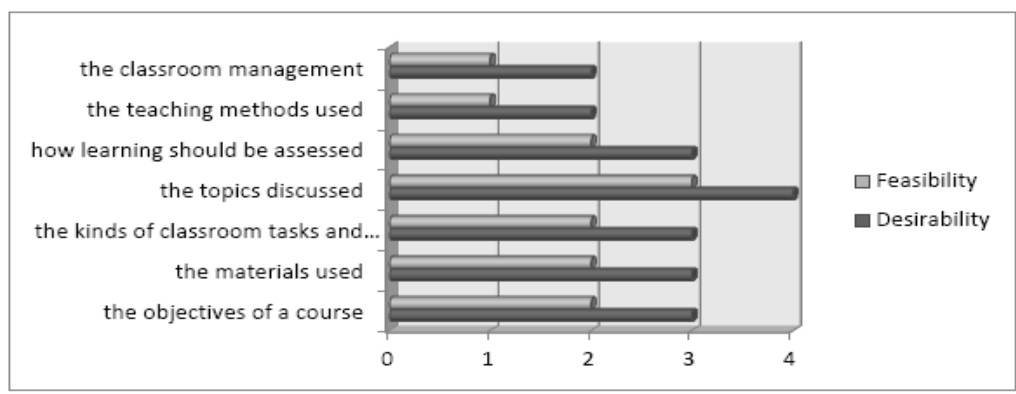

Figure 5.3. The Frequency Graph of Desirability and Feasibility of Student Involvement in Decision-Making Based on Teachers' Point of View ( $1=$ Undesirable/Unfeasible; 4=Very Desirable/Feasible)

The above figure summarizes the teachers' responses and shows that in all cases teachers were more positive about the desirability of student involvement than they were about its feasibility. Student involvement in decision making was seen to be most feasible and desirable in relation to topics, and least feasible and desirable in relation to classroom management and teaching methods.

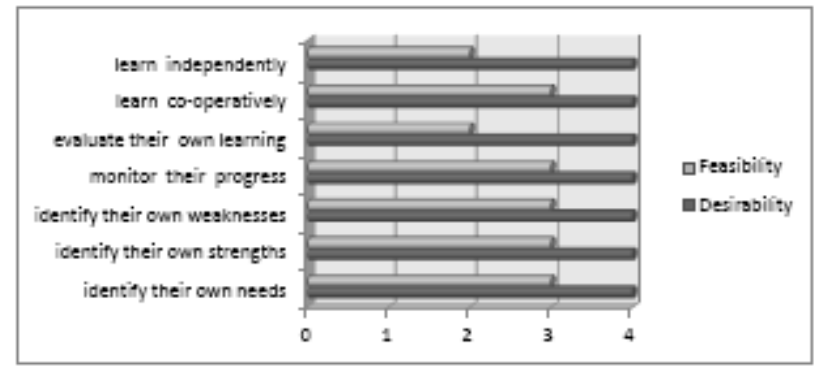

Figure 5.4. The Frequency Graph of Desirability and Feasibility of Learners Abilities Based on Teachers' Point of View (1=und esirable/unfeasible; 4=very desirable/feasible)

The second part of this section asked teachers how desirable and feasible they felt it was for their students to develop a range of abilities that were commonly seen as indicators of learner autonomy. The above figure shows the results of this comparison. Once again, desirability was consistently higher than feasibility of the students'abilities in all cases. In contrast to the previous set of items, all those listed here were considered desirable for learners.

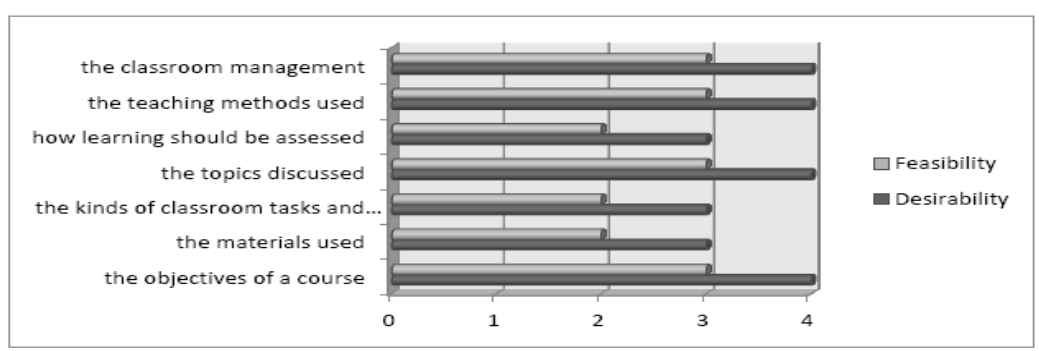

Figure 5.5The Frequency Graph of Desirability and Feasibility of Student Involvement in Decision-Making Based on Learners' Point of View (1=Undesirable/Unfeasible; 4=Very Desirable/Feasible

The above figure summarizes the learners' responses and shows that in all cases learners were more positive about the desirability of student involvement than they were about its feasibility. Student involvement in decision making was seen to be most feasible and desirable in relation to topics, classroom management, teaching methods, and objectives of the course. On the other hand, student involvement in decision making was seen to be the least feasible and desirable in relation to materials, classroom tasks and assessment. 


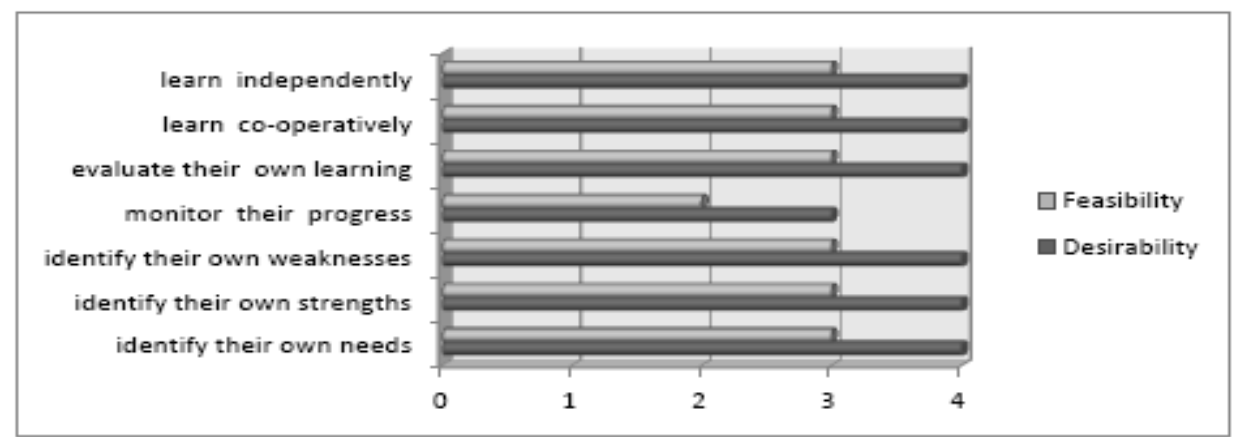

Figure 5.6. Desirability and feasibility of Learners Abilities Based on Learners' Point of View (1=undesirable/unfeasible; 4=very desirable/feasible)

The above figure shows the results of the learners' Point of View on how desirable and feasible they felt it was to develop a range of abilities that are commonly seen as indicators of learner autonomy. Desirability was again consistently higher than feasibility of the students' abilities in all cases.

\section{Addressing the Fifth Research Question}

Are There any Significant Differences between L2 Teachers' and Learners' Beliefs Regarding the Degree of L2 Learning Enhancement through Autonomy and Desirability and Feasibility of L2 Learning Autonomy Promotion?

For the purpose of answering the final research question, inferential statistics were applied. In order to answer the first part of the final question which is about contrasting the teachers' and learners' views on the effect of learner autonomy on L2 learning, before comparing the mean of the variable (does learner autonomy enhance L2 learning which is the result of adding the item number 8 and 21), the Levene's test for equality of variances should have been applied.

TABLE 5.1.

THE RESULT OF LEVENE'S TEST FOR EQUALITY OF VARIANCES

\begin{tabular}{ccc}
\hline Variable & F & Sig \\
\hline learner autonomy would enhance L2 learning & 3.5 & 0.062 \\
\hline
\end{tabular}

Since the amount of sig is more than 0.05 , the variance in the two groups of teachers and learners is equal. Considering the equality of the variances, it is allowed to compare the teachers' and learners' views about the effect of learner autonomy on L2 learning.

TABLE 5.2.

\begin{tabular}{|c|c|c|c|c|c|c|c|}
\hline \multirow[t]{2}{*}{ Variable } & \multirow[t]{2}{*}{$t$} & \multirow[t]{2}{*}{ df } & \multirow[t]{2}{*}{ sig } & \multirow[t]{2}{*}{$\begin{array}{c}\text { Mean } \\
\text { Difference }\end{array}$} & \multirow[t]{2}{*}{$\begin{array}{l}\text { Std. Error } \\
\text { Difference }\end{array}$} & \multicolumn{2}{|c|}{$\begin{array}{l}95 \% \text { Confidence } \\
\text { Interval of the } \\
\text { Difference }\end{array}$} \\
\hline & & & & & & Lower & Upper \\
\hline $\begin{array}{l}\text { learner autonomy } \\
\text { would enhance L2 } \\
\text { learning }\end{array}$ & 2.719 & 289 & 0.007 & 0.393 & 0.145 & 0.109 & 0.678 \\
\hline
\end{tabular}

Regarding the amount of sig (p-value $<0.05$ ) it can be concluded that the teachers and learners do not have exactly the same idea about the effect of learner autonomy on L2 learning.

The last part of final question deals with comparing the teachers' and learners views about the desirability and feasibility of the learner autonomy.

TABLE 5.3.

THE MEAN OF DESIRABILITY AND FEASIBILITY

\begin{tabular}{cllcc}
\hline Variable & Groups & Mean & Std. Deviation & Std. Error Mean \\
\hline Desirability & Teacher & 40.49 & 9.025 & 0.737 \\
& Leamer & 40.95 & 7.350 & 0.600 \\
\hline Feasibility & Teacher & 31.06 & 7.848 & 0.641 \\
& Leamer & 34.22 & 7.232 & 0.590 \\
\hline
\end{tabular}




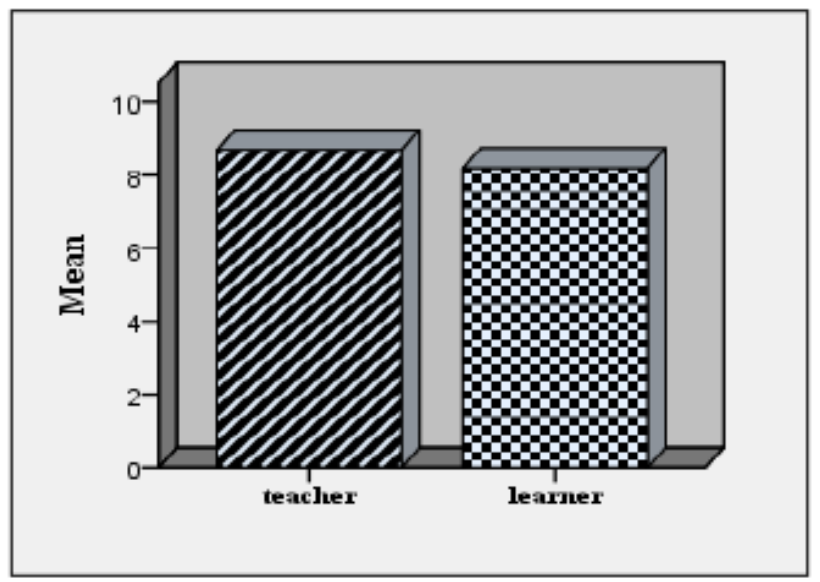

Figure 5.7. The Frequency of Desirability

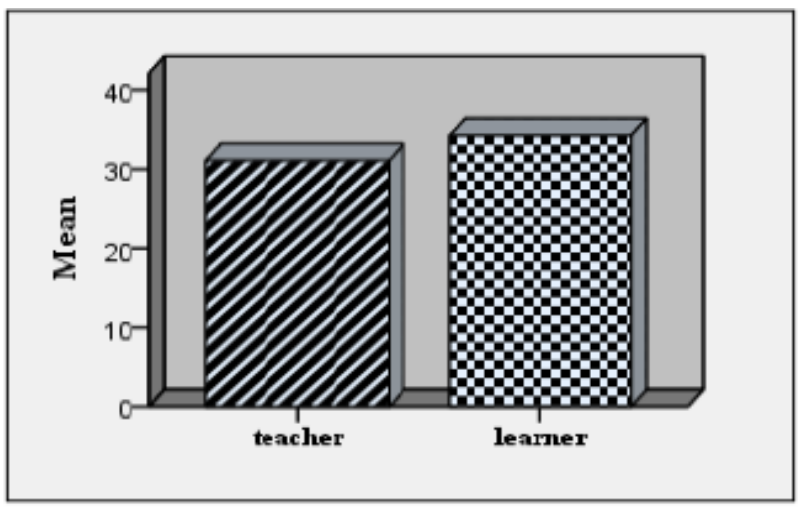

Figure 5.8. The Frequency of Feasibility

The above table and bar graphs show the amount of descriptive statistics (mean) for the two variables (desirability and feasibility) in two groups of teachers and learners. Now in order to see if based on teachers' and learners' views the promotion of L2 learner autonomy is desirable and feasible the Two-independent sample test was used. Prior to draw a comparison, Levene's test for equality of variances should be done.

TABLE 5.4.

THE RESULT OF LEVENE'S TEST FOR EQUALITY OF VARIANCES

\begin{tabular}{ccc}
\hline Variable & F & Sig \\
\hline Desirable & 7.372 & 0.007 \\
Feasible & 3.424 & 0.065 \\
\hline
\end{tabular}

Owing to the fact that variances for desirability are not equivalent but are equivalent for feasibility, the comparison of teachers' and learners' views about desirability and feasibility has been done.

TABLE 5.5.

THE RESUlts OF Two INDEPENDENT SAMPLE TEST FOR DESIRABILITY AND FEASIBILITY

\begin{tabular}{|c|c|c|c|c|c|c|c|}
\hline \multirow[t]{2}{*}{ Variable } & \multirow[t]{2}{*}{$t$} & \multirow[t]{2}{*}{$\mathrm{Df}$} & \multirow[t]{2}{*}{ sig } & \multirow{2}{*}{$\begin{array}{c}\text { Mean } \\
\text { Difference }\end{array}$} & \multirow{2}{*}{$\begin{array}{l}\text { Std. Error } \\
\text { Difference }\end{array}$} & \multicolumn{2}{|c|}{$\begin{array}{c}95 \% \text { Confidence } \\
\text { Interval of the } \\
\text { Difference }\end{array}$} \\
\hline & & & & & & Lower & Upper \\
\hline Desirability & -0.484 & 286.264 & 0.629 & -0.460 & 0.950 & -2.330 & 1.410 \\
\hline Feasibility & -3.626 & 298 & 0.000 & -3.160 & 0.871 & -4.875 & -1.445 \\
\hline
\end{tabular}

Regarding the amount of obtained sig for feasibility ( $\mathrm{p}$-value $<0.05$ ), it can be concluded that there is not a significant difference between teachers' and learners' views. Also, due to the amount of obtained sig for desirability, it can be concluded that there is a significant difference between teachers' and learners' views in this regard. 


\section{DISCUSSION}

\section{A. Addressing the Third Research Question}

In the questionnaire 62.7 percent of the learners and 80 percent of teachers agreed that learner autonomy allows language learners to learn more effectively than they otherwise would. Moreover, 92 percent of the teachers agreed that learner autonomy has a positive effect on being a successful language learner, while 94 percent of the learners agreed that learner autonomy learner autonomy has the above effect. Therefore, the two groups came in to an agreement that learner autonomy has a strong positive effect on L2 learning.

- In the interviews the teachers and learners were asked to provide justifications for their positive views. They suggested a number of relationships between learner autonomy and successful language learners in the following:

- The teachers as well as the learners thought that autonomous learners are more motivated. Teachers also added, the more autonomous the learners are, the more motivated they can be. So learner autonomy can strongly influence the learners' ability to learn a language well.

- Autonomous learners are more dedicated and responsible. They do not need their teachers to make them forced to do their homework. They themselves are willing to take the responsibility of their own learning.

- Autonomous learners are able to concentrate on their own learning so they can independently learn.

The obtained results which contribute to teachers' ideas go in line with the results reported by Borg and Al-Busaidi (2012). In their questionnaire, 93.4 percent of the teachers agreed that learner autonomy has a positive effect on their success as a language learner, while 85.2 per cent agreed that learner autonomy allows language learners to learn more effectively than they otherwise would. Overall, then, the teachers expressed strong positive views about the contribution of learner autonomy to language learning. Besides the reasons they gave in the interview were almost like the one the participants of this study gave.

\section{B. Addressing the Fourth Research Question}

The results show that in all cases teachers were more positive about the desirability of student involvement than they were about its feasibility. Student involvement in decision making was seen to be the most feasible and desirable in relation to topics, and the least feasible and desirable in relation to classroom management and teaching methods.

The comparison between desirability and feasibility of the learners' abilities which are the indicators of learner autonomy indicated that once again, desirability was consistently higher than feasibility of the students' abilities in all cases. In contrast to the previous set of items, all those listed here were considered desirable for learners.

These results to some extent overlap with the results of Borg and Al-Busaidi's (2012). The results obtained from the interviews support these results since the participants exclaimed everything contributes to learner autonomy is desirable but its feasibility is under question (because of educational systems and other obstacles).

\section{Addressing the Fifth Research Question}

Considering the results obtained from the first part of the final question which is about contrasting the teachers' and learners' views on the effect of learner autonomy on L2 learning, it can be concluded that the teachers and learners do not have exactly the same idea about the effect of learner autonomy on L2 learning. However this difference is not too big. The interview results revealed that this difference is related to the way the teachers and learners perceive the concept of learner autonomy.

Paying attention to the results obtained from the last part of final question which deals with comparing the teachers' and learners views about the desirability and feasibility of the learner autonomy, it can be inferred that there is not a significant difference between teachers' and learners' views about feasibility. On the other hand, due to the results obtained for comparing the teachers' and learners' views' about desirability of the autonomy, it can also be concluded that there is a significant difference between teachers' and learners' views in this regard. In the interviews the two groups of participants expressed that all the factors and conditions contributing to learner autonomy are really desirable but because of the traditional educational system in Iran they are not really feasible.

\section{CONCLUSION}

As discussed earlier, despite a substantial amount of research over some 30 years, research on learner autonomy has paid limited attention to the sense teachers make (as well as comparing teachers' and learners' senses), theoretically and in practice, of this concept. Yet, without such insights, we lack a basis for understanding how teachers interpret the notion of learner autonomy and where necessary for encouraging them to make it a more central aspect of their work. The following is a summary of the salient findings to emerge here which in most cases overlap with the findings of the study done by Borg and Al-Busaidi (2012).

One of the salient findings of the study was that the teachers and the learners positively agreed (as in Bullock, 2011; Camilleri, 1999; Yoshiyuki, 2011) on the notion of learner autonomy and its highly effective advantages specifically for language learners.

As Borg and Al-Busaidi mentioned in their research, there was a significant gap between the extent to which teachers felt it was desirable to involve learners in a range of decisions about their learning and teachers' beliefs about the 
feasibility of doing so, particularly in relation to objectives, assessment and materials. However the two groups of participants in this study agree on desirability of learner autonomy in general.

Regarding the gained results from the interviews, the teachers highlighted some of the factors which limited the extent to which they felt they were able to promote learner autonomy. These are related to learners, the institutions and teachers, though learner-related factors were those most widely cited by the teachers. whereas teachers felt that their students did not understand the importance of developing autonomy, and some thought because of the educational system in our country most of the students expect their teachers to play the main role in the class and if the teacher tries to hand over some part of this responsibility to students, they think he or she is not an active well- experienced teacher. Some others mentioned that they are not allowed to have creativity and they have to just observe the rules of the educational system in which they work. However some argued that they need to attend in some in-service training courses to teach them how to develop learner autonomy in their classes.

\section{REFERENCES}

[1] Al-Shaqsi, T. S. (2009). Teachers' beliefs about learner autonomy. In S. Borg (Ed.), Researching English language teaching and teacher development in Oman, (pp. 157-165). Muscat: Ministry of Education, Oman.

[2] Andreu, C.T. (2007). Student's Autonomous Activities in Multidisciplinary Registers Learning. International Conference on Engineering Education - ICEE, 2(3) ,pp.3-7

[3] Balcikanli, C. (2007). The Investigation of the Instructors' Attitudes toward Learner Autonomy at Preparatory School. In Proceedings of Language teaching and learning in multilingual Europe. Vilnius: Lithuania.

[4] Benson, P. \& Voller, P. (1997). Autonomy and Independence in Language Learning. London: Longman.

[5] Borg, S. (2003). Teacher cognition in language teaching: a review of research on what language teachers think, know, believe, and do. Language Teaching, 36(2), 81-189.

[6] Bullock, D. (2011). Learner self-assessment: An investigation into teachers' beliefs. ELT Journal 62(2), pp.114-125.

[7] Camilleri, G. (1999). Learner autonomy: The teachers' views. Retrieved 20 January 2013, from http://archive.ecml.at/documents/pubCamilleriG_E.pdf.

[8] Chan, V. (2003). Autonomous language learning: the teachers' perspective. Teaching in Higher Education, 8(1), pp. 33-48.

[9] Dörnyei, Z., \& Taguchi, T. (2010). Questionnaires in second language research: Construction, administration and processing (2nd ed.).New York: Routledge.

[10] Esch, E. (1998). Promoting learner autonomy: Criteria for the selection of appropriate methods. In R. Pemberton, E. S. L. Li, W. W. F. Or \& H. D. Pierson (Eds.), .Taking control: Autonomy in language learning (pp. 35-48). Hong Kong: Hong Kong University Press.

[11] Martinez, H. (2008). The subjective theories of student teachers: Implications for teacher education and research on learner autonomy. In T. E. Lamb \& H. Reinders (Eds.), Learner and teacher autonomy: Concepts, realities, and responses (pp. 103124).Amsterdam: John Benjamins.

[12] Nakata, Y. (2010). Towards a framework for self-regulated language-learning. TESL Canada Journal, 27(2), pp.1-10.

[13] Oxford, R. L. (2003). Toward a more systematic model of L2 learner autonomy. In D. Palfreyman \& R. C. Smith (Eds.), Learner autonomy across cultures: 138

[14] Palfreyman, D, \& Smith, R. (2003). Learner Autonomy across Cultures: Language Education Perspectives. New York, New York: Palgrave MacMillan

[15] Palfreyman, D. (2003). Introduction: Culture and learner autonomy. In D. Palfreyman \& R. C. Smith (Eds.), Learner autonomy across cultures: Language education perspectives (pp. 1-185). Basingstoke: Palgrave Macmillan.

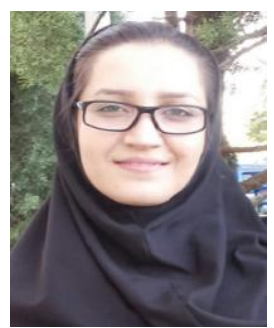

Somayeh Shahsavari, MA holder in English Language Teaching, With more than 10 years of experience in teaching, the co compiler of the books Song Time, Alphabet Time, Songs for First Graders as well as My First Alphabet \& Songs Series, and the writer of some articles in different journals of teaching English. 